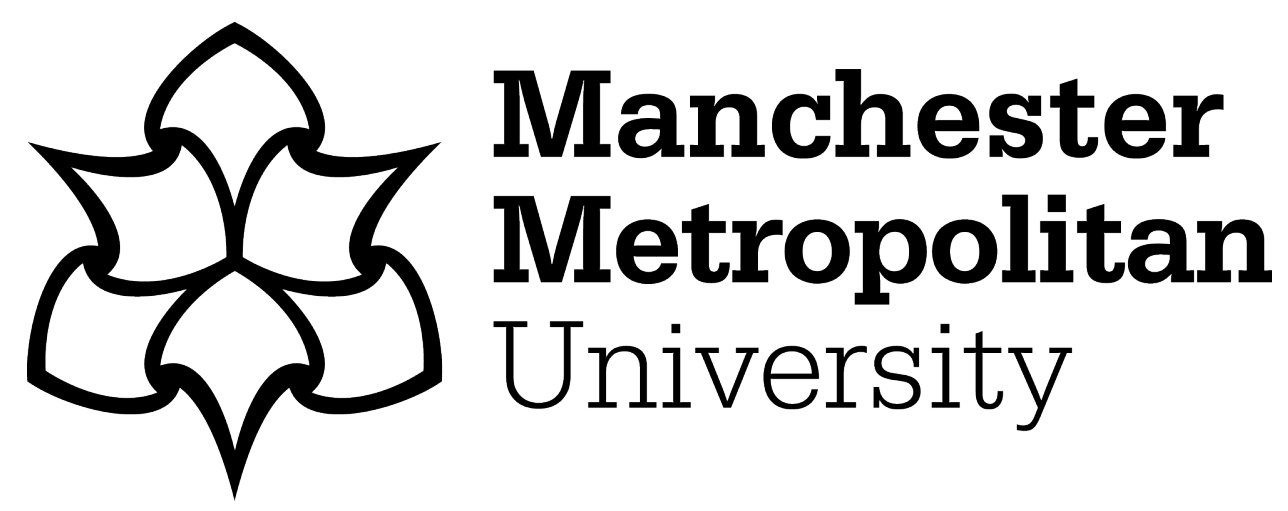

Olya, Hossein, Jung, Timothy ORCID logoORCID: https://orcid.org/00000002-8594-6641, tom Dieck, M ORCID logoORCID: https://orcid.org/00000002-8765-8969 and Ryu, Kisang (2020) Engaging Visitors of Science Festivals Using Augmented Reality: Asymmetrical Modelling. International Journal of Contemporary Hospitality Management, 32 (2). ISSN 0959-6119

Downloaded from: https://e-space.mmu.ac.uk/624703/

Version: Accepted Version

Publisher: Emerald

DOI: https://doi.org/10.1108/IJCHM-10-2018-0820

Please cite the published version 


\title{
Engaging visitors of science festivals using augmented reality: Asymmetrical modelling
}

\begin{abstract}
Purpose: This empirical study explores a complex combination of four realms of the experience economy in formulating memories and satisfaction among festival visitors using augmented reality (AR), thus engaging visitors in the physical science experience. This study also identifies necessary conditions to achieve desired responses from visitors.

Design/methodology/approach: Asymmetrical modelling with fuzzy set qualitative comparative analysis (fsQCA) was used to investigate causal recipes of two configurations of the experience economy and evaluation of experience leading to both high and low scores from visitor engagement. Necessary condition analysis (NCA) was applied to examine necessary predictors in visitor engagement. The proposed configuration model was tested using data obtained from visitors to science festivals in the UK.
\end{abstract}

Findings: Five causal recipes explained the complex conditions in which visitors were more likely engaged in AR. Aesthetics, education, entertainment, and satisfaction were necessary for high engagement among festival visitors.

Research limitations/implications: Results from fsQCA and analyses of necessary conditions help festival organizers improve visitor satisfaction and engagement in a memorable AR experience.

Originality/value: This empirical study deepens current festival understanding of how visitors experience AR by exploring combinations of complex configurations of the experience economy and evaluations of visitor experience based on memories and satisfaction. Unlike symmetrical approaches, asymmetrical modeling using fsQCA can explore recipes for both high and low 
scores of visitor satisfaction and engagement. This is the first empirical study investigating necessary predictors of festival visitor behavior.

Keywords: Augmented reality; configurations; festival; fsQCA; necessary condition; engagement.

\section{Introduction}

Research has increasingly shown that science festivals can benefit visitor economies, with strong effects on destinations (Bultitude, 2014). One set of recent success stories in the festival industry are the science festivals thriving in Europe that educate and engage visitors in scientific knowledge. These science festivals are a driver for tourism, but to be successful, science festival organizers must pay special attention to the level of visitor engagement (Stilgoe et al., 2014). Recently, information communications technologies (ICTs) have become increasingly important in attracting and entertaining visitors during such festivals (Georgiou and Kyza, 2017). Augmented reality (AR) is one technology that could change the way visitors experience their surroundings (Han et al., 2014), but understanding of how memories, satisfaction, and engagement are modeled using AR at science festivals is relatively unexplored to the best of our knowledge.

AR, the digital enhancement of the direct surroundings, offers new opportunities for enhancing visitor experiences (Chung et al., 2015). The recent success of AR can be linked directly to applications like Pokémon Go, which led to increased interest in AR in everyday life (Rauschnabel et al., 2017). Nevertheless, although AR applications have become increasingly popular, research to date has primarily focused on how users adopt the technology (Haugstvedt and Krogstie, 2012; Rauschnabel et al., 2017), user satisfaction with the technology (Chung et 
al., 2015), or application design, while little research has been done on the level of engagement among tourists.

Tourism has seen a steady shift from simply offering a tourism product and/or service to staging tourism experiences (Neuburger and Egger, 2018). Pine and Gilmore (1998) introduced the concept of an experience economy and conceptualized four realms of that experience, classified by a spectrum of connections and participation. The four realms are aesthetics, education, escapism, and entertainment. A number of scholars have adopted this experience economy concept. For instance, using structural equation modelling (SEM), previous research has explored the effects on the overall tourism experience (e.g., Hosany and Witham, 2009; Oh et al., 2007) or on well-established constructs like tourist loyalty (e.g., Manthiou et al., 2014), but the complex combination of the four realms of the experience economy concept on memories, satisfaction, and visitor engagement remains unexplored.

Nonetheless, few empirical studies have attempted to identify which realm of the experience economy contributes to memories, satisfaction, and engagement, especially for science festival visitors who experience AR (e.g., tom Dieck et al., 2018). tom Dieck et al. (2018) tested the AR experience economy model using SEM. They discovered how the four realms of the experience economy affect memories and satisfaction and ultimately visitor engagement. As part of their study, tom Dieck et al. recommended "configuration analyses as a potential alternative to the standard regression-based net effects models (e.g. regression or SEM) [...] to identify complex and asymmetric relations between constructs" (2018, p. 52). Specifically, including the demographics of visitors increases the complexity of the model. Applying asymmetrical modeling leads to higher explanatory powers in models and provides stronger insights into the driving factors of tourism experiences. 
Hence, this empirical study applies two advanced analytical approaches, beyond symmetrical methods, to model memories, satisfaction, and engagement among science festival visitors. This study deepens our current understanding of festival visitor engagement by calculating algorithms from combinations of experience economy and experience evaluations factors. Unlike symmetrical approaches (e.g., SEM), asymmetrical modelling (e.g., fuzzy-set qualitative comparative analysis or fsQCA) helps in investigating both high and low scores of visitor engagement. Specifically, fsQCA enables scholars to address several concerns in applying symmetrical methods, such as multicollinearity issues, normality of data, large sample size, and overlooking occurrences of contrarian cases (Olya and Altinay, 2016; Olya et al., 2018; Olya and Gavylian, 2017). One shortcoming of the asymmetrical method refers to considering net effect of an indicator on the high outcome score as mirror opposite of net effect of given indictor on low outcome score (Olya et al., 2018).

The current study is unique in using a rather new asymmetrical approach that not only overcomes the limitations of previous studies on AR and festival management, but also creates knowledge by exploring causal recipes that explicate different insights into visitor engagement. Woodside (2014, p. 2502) indicated that “... prior studies (e.g., Armstrong, 2012; Bass et al., 1968; McClelland, 1998; Montgomery, 1975) identify serious problems with the near total reliance by most researchers on symmetric statistical tests and difficulties in achieving theory advances relying on such tools. Gigerenzer (1991) and McClelland (1998) call attention and demonstrate the value of using asymmetric tests to both advance theory as well as provide useful empirical models of the occurrence of multiple realities. Ragin (2008) has been the principal advocate in the behavioral sciences along with Gigerenzer (1991) and Armstrong (2012) on advancing new competencies in the theory and research relevant for advancing theory-crafting 
and analytical skills of academic researchers in the sub-disciplines of management. Because the body of work and rigorous tools relating to complexity theory applications and fsQCA is growing in the management sub-disciplines, the present dominant logic of MRA/ SEM and survey research features described in this essay will end during the second decade of the 21 st century".

This study extends a recent study of tom Dieck et al. (2018) by using demographics and prior experience of visitors in the configurational model and applying an asymmetrical approach to deepen our understanding of causal recipes leading to visitor engagement in the context of the experience economy and festival management. Specifically, this study aims to address the following research questions: What conditions (e.g., engagement) describe recipes for high level of visitor engagement using AR at science festivals? What recipes adequately explain low level visitor engagement? What conditions are necessary to achieve the expected outcomes (particularly engagement)? fsQCA shows adequate recipes for visitor engagement in the science festival environment. To ensure the originality of the paper, a further analysis was conducted to identify the necessary conditions for engaging visitors. While fsQCA calculated adequate causal recipes (with combinations of factors), necessary condition analysis (NCA) was used to investigate the necessity of the factors. Necessary factors are those factors without which the outcome (engagement) will not be obtained. To the best of our knowledge, few empirical studies used both fsQCA and NCA to model visitor engagement at science festivals using augmented reality. This not only extends our understanding of necessary conditions, but also helps festival managers to improve visitor's engagement.

\section{Theoretical Background}

Augmented reality and tourism and festival experiences 
Technology has been recognized and used to engage festival audiences. Coachella, one of the most popular US music festivals, started to provide audiences with Google boards to create immersive 360-degree music experiences, also enabling a larger audience that did not have tickets to experience music acts and the actual festival atmosphere. RFID wristbands are another technology in the festival market that allows immersive and seamless experiences by guiding festival goers, enabling payment and proximity-based notifications (Thompson, 2016). Nevertheless, considering the recent popularity of AR applications, their use in festivals has been relatively limited. AR refers to "how 3D virtual objects are integrated into a 3D real environment in real time" (Azuma, 1997, p. 355) and its potential in tourism has been widely discussed (Tussyadiah et al., 2017). A recent study by Han et al. (2016) explored the tourist experience through AR, praising AR for its ability to overcome language barriers, navigate, educate, offer entertaining and accessible content, and personalize information. In addition, Han and Jung found that information communication technologies (ICTs) like AR "support the sustainability of cultural heritage sites and increase their competitiveness in the global market" (2017, p. 4). Destinations and visitor attractions worldwide have increasingly implemented AR, and local communities and city councils have been quick to see the potential and use this new way of engaging tourists (Chapman, 2017). Lately, Pokémon Go, a form of AR gaming, has demonstrated a new layer of interactivity in the tourist experience, allowing tourists to chase Pokémons to unknown locations and permitting them to explore many destinations (Zach and Tussyadiah, 2017). Overall, AR provides tourists with an entertaining, educational, and informative way to explore tourism products and services (Moorhouse et al., 2017). The role of $\mathrm{AR}$ in tourism is further expanded and developed as part of smart tourism to provide information 
on tourism destinations and tourist attractions for maximization of tourist satisfaction (Chung et al., 2015).

Events and festivals are a growing sector in tourism, recognized as a main driver promoting tourism and boosting the visitor economy (Felsenstein and Fleischer, 2003). As a form of tourism, events and festivals depend highly on visitor engagement. According to Pan and Huan (2013), creating memories and stories makes events an important tourism activity. Nicholson et al. (2001) explored festival goer motivations and found the following: the desire to explore something new, socializing, entertainment, escaping, family, and specific festival interest. Recently, several researchers have been interested in evaluating technology for storytelling and evoking memories (Shin, 2018). In addition, socializing, escapism, and entertainment are commonly identified as part of ICT and event research (Manthiou et al., 2014; Mehmetoglu and Engen, 2011; tom Dieck et al. 2018). Stankow et al. (2018) explored the increased use of ICTs at events and distinguished between two general approaches, visitor-centric applications and managerial ones. The first mostly relates to enhancing pre- and during festival experience by providing interactive information for personalized communication, whereas the latter is more for festival management. Using applications for delivering better experiences at events has been a trend over the past few years (van Winkle et al., 2018). This is particularly important because, according to Robertson et al. (2015), many festivals and events fail as they miss the opportunity to effectively engage visitors. Recently, AR has been considered a useful tool to enhance on-site visitor experiences at events and festivals; virtual reality, on the other hand, is more useful for practitioners who use AR for festival visitor experiences and engagement (tom Dieck et al., 2018).

Visitor engagement at science festivals 
According to Bultitude et al. (2014, p. 166), science festivals are "a particular type of science communication event characterized by an ephemeral nature, localized to a specific venue, town or region"; their primary objective is to engage non-specialist visitors (Bultitude et al., 2014). AR can benefit science festivals by engaging visitors, immersing and educating them, and thus making it a strong ICT for the festival context. Visitor engagement at science festivals has two advantages for science. First, researchers must involve the public with science to rebuild trust after recent negative initiatives and research experiments. An example of this includes scientific dishonesty or non-disclosed conflicts of interests (Leshner, 2003; Stilgoe et al., 2014). Second, and more relevant for the tourism and festival industry, AR is a promising tool for telling hidden stories (Han et al., 2014). Thus, destinations worldwide can present past achievements to provide memorable and educational experiences to tourists. One example is Manchester, the European City of Science in 2016, with its close links to universities and achievements in winning prizes for scientific research, including the Nobel Prize. Visitors are unaware of these achievements. Ample history and a legacy of science and scientists in Manchester means visitors can experience the hidden stories of scientist (e.g., Alan Turing or John Dalton) when they scan the statue of scientists via AR. According to Kouper (2010), ICTs can facilitate a wider involvement in science, with applications showcasing science projects while stimulating interest. This can help science festivals to create unique visitor engagement with a theme such as a science heritage trail to attract more visitors (Han et al., 2014).

Experience economy

The theoretical foundation of the experience economy lies in the theory of experienced utility (Kahneman \& Thaler, 1991), whereby utility refers to the overall benefits visitors receive from an experience (Kim et al., 2019). According to Chang (2018a), the theory of experienced utility 
suggests that experiences are highly emotional and therefore visitors are likely to have stronger experiences when they experience hedonic pleasures. Linking it to the experience economy, it is suggested that "emotion precedes rationality and thus that future prediction and decision making are based on an assessment of hedonic quality" (Chang, 2018b, pp. 83).

The experience economy framework began evolving in 1998 when Pine and Gilmore found a change in consumer behavior. Rather than simply consuming products and services, consumers shifted toward a more active role in the co-creation of value. Out of this, the idea of the experience economy was born. As Figure 1 shows, Pine and Gilmore (1998) proposed a framework that explains experiences on a spectrum, with connection on the vertical and participation on the horizontal axes (Pine and Gilmore, 1998). Quadri-Felitti and Fiore (2013, p. 48) noted that customers can be active participants, directly affecting events, or passive participants, simple receivers of products and services but clearly acknowledged that consumers fall somewhere within the spectrum.

\section{--- Insert Figure 1 Here ---}

For the context of this study, education can be defined as an "activity involving the pursuit of understanding, knowledge or skill which occurs outside the curricula of educational institutions, or the courses or workshops offered by educational or social agencies" (Schugurensky, 2000, p. 1). According to Oh et al. (2007), in the educational realm, tourists gain new skills or knowledge by actively engaging in tourism activities. Previous scholars have noticed that AR can be a tool for education. Moorhouse et al. (2017), for instance, discussed its strength in providing engaging content. Second, users in the entertainment realm prefer to use 
applications to have enjoyable tourism experiences. According to Wikstreom (2008, p. 40), entertainment can be defined as "something that amuses, pleases, or diverts (especially a performance or show), or as the pleasure afforded by being entertained and amused". Jung et al. (2016) linked this to the passive delivery of content. Third, in the context of this study, escapism can be defined as "the escape of [tourists] regular environments to suspend the power of norms and values that govern their ordinary lives or to think about their lives and societies from a different perspective" (Oh et al., 2007, p. 122). This relates to active participation in creating and delivering tourism services and products, being fully immersed in experiences, and therewith forgetting about daily life, which is often linked to virtual reality applications (Song et al., 2015). Fourth, aesthetics has become more important as part of ICT-enabled tourism experience, involving technology design and a pleasant interface (Jung et al., 2016). According to Lee et al. $(2015$, p. 481$)$, aesthetics relates to "the beauty that can be expressed through the elements such as color, photographs, font style, and layout." However, the richest experiences are, according to Neuburger and Egger (2018), those experiences that offer all four elements of the experience economy. In the context of tourism and leisure, previous studies revealed that past experience influences future tourism decisions (Mazursky, 1989), recreation behavior (Schreyer et al., 1984), and revisit intentions (Huang and Hsu, 2009).

Previous studies, using SEM, found that any or all four realms affect tourist satisfaction, vividness, loyalty, or memories of tourism experiences (Manthiou et al., 2014; Mehmetoglu and Engen, 2011; Oh et al., 2007). Rivera et al. (2015) noted how few studies have been conducted using the experience economy as a foundation within the festival context. Table A1 provides an overview of previous experience economy studies within the festival context. From the summary, it becomes clear that many studies focused on music festivals. According to Rivera et al. (2015), 
these festivals often attract a younger audience that is particularly interested in the co-creation of value and participation in the experience process; hence, music festivals are an important part of experience economy research in the tourism field. The summarized studies explored the effect of the experience economy on behavioral intention, word of mouth, loyalty, or satisfaction, with some studies incorporating mediating variables such as vividity, satisfaction, and memorable experiences (e.g., Manthiou et al., 2014; Semrad and Rivera, 2018). Interestingly, Park et al. (2014) confirmed a mediating effect of escapism within the film festival context, which had not been explored previously. This might be due to the particular nature of film festivals and the escape from reality watching films and reenactments provides. This, in turn, shows that different types of festivals result in different experience economy configurations. With regards to experience economy dimensions, one can assume that music and film festivals are primarily entertainment and escapism related. Specifically people will engage with them in a mind-set of leisurely enjoyment. Science festivals are aimed at providing primarily a learning experience with the added benefit of being a joyful experience. There is no doubt some overlap as to motivations of visitors to attend either film or music festivals and science festivals but the primary objective is distinctly different when viewed through the lens of the experience economy.

Most festival and experience economy studies have used SEM to assess the suitability of the four constructs within the given context. Also, tom Dieck et al. (2018) tested a structural model including four realms within the science festival context: change, memories, satisfaction, and visitor engagement. However, using configurational modelling in the context of experience economy and tourism is new and unexplored. Specifically, Woodside (2014) criticized symmetrical analysis (e.g., SEM) because it has serious shortcomings that lead to misleading outcomes. 
Using a multi-analysis approach, this empirical study serves several purposes. First, it explores recipes of AR experience to explain conditions leading to high levels of satisfaction, memories, and visitor engagement with science. Second, this study evaluates conditions (i.e., recipes for outcome negation) leading to low levels of memories, satisfaction, and engagement. Third, this study identifies which factors must be satisfied to engage visitors, allowing a memorable visit. This study applies fsQCA and NCA to identify adequate recipes and necessary predictors (i.e., aesthetics, entertainment, education, and escapism) of visitor satisfaction and engagement in science festivals using AR. This not only extends our understanding of necessary conditions, but also helps festival managers meet essential criteria to satisfy and engage visitors.

\section{Demographics and visitor behaviors}

The literature supports demographics having an effect on individual behaviors (e.g., Islam, Rahman, and Hollebeek, 2018; Gim and Ramayah, 2019; Olya et al. 2019; Olya et al., 2018). For example, Islam et al. (2018) found that younger visitors may be less engaged with tourism activities in India. Gim and Ramayah (2019) reported an association between age and undesirable behavioral intentions among respondents. In terms of gender, Olya and Akhshik (2019) noted that female tourists are most likely to become engaged by pro-environmental practices in North Cyprus. In the context of heritage site, Olya et al. (2019) reported that female and educated visitors are more satisfied and loyal to heritage. They also found age and marital status played both positive and negative roles in predicting satisfaction and loyalty. In contrast, Al-Ansi et al. (2019) indicted that satisfaction and behavioral intentions of male patrons in Malaysian restaurants is more desired than female. They also found that single and educated patrons have more trust comparing coupled/married once. One recent study argues that income 
and education level negatively contributed to desired behavioral intentions of travelers. The study found heterogeneous results for role of gender and prior experience in predicting behavioral intentions of travelers to North Cyprus (Olya et al., 2018). Gannon et al. (2019) used past visitor experience in predicting visitor's behavior at Cappadocia festival in Turkey, finding that prior experience positively contributes in forming both experience and word of mouth. Recent studies have also called for considering demographics of consumers as predictors of their behaviors in service context (e.g., Ostrovskiy, Garkavenko and Rybina, 2019; Rather, Hollebeek, and Islam, 2019). Bronfenbrenner's (1994) ecological systems theory explains how individuals characteristic (e.g., demographics) along with environmental factors can affect their affective and behavioral responses. With this realization, we used demographics as a causal configuration to predict memories, satisfaction, and engagement of science festival visitors in the UK.

\section{Configurational Model}

Venn diagrams were used to design the proposed configurational model (Figure 2). The configurational model comprises three causal configurations: 'demographics', the 'experience economy', and 'evaluation of experience'. Age, gender, educational level, income level, and marital status are elements of demographic configurations. Experience economy configuration consisted of aesthetics, education, entertainment, and escapism, and the 'evaluation of experience' configuration used satisfaction, memories, and past experience to predict high and low scores for visitor engagement. Effects of demographics configuration on memories is represented by arrow A, satisfaction by arrow B, and engagement by arrow $\mathrm{C}$. The influence of the AR experience economy configuration on memories is represented by arrow $\mathrm{D}$ and satisfaction by arrow E. Arrow F indicates the causal effect of experience evaluation 
configuration on visitor engagement. Arrow G shows complex interactions of the experience economy and experience evaluation configurations in predicting visitor engagement with the festival.

\section{--- Insert Figure 2 Here ---}

\section{Methodology}

Study context

Manchester, in the UK, was chosen as European City of Science (ECOS) in 2016 because of its history of scientific inventions. Thus, an application was developed initially for the ECOS festival to enhance visitor experience to the city during the festivities as well as after the ECOS festival; it was further modified and available for visitors to the annual Manchester Science Festival. The app provides information on science events as well as the history of science in Manchester. In addition, and related to this study, AR is one of the main functionalities of the application.

\section{Measurements, data, and procedures}

Scale items for 4 realms of experience economy, memories, satisfaction, and engagement were adapted from previous studies (Jung et al., 2016; Loureiro, 2014; Quadri-Felitti and Fiore, 2013) to fit the context of this study. All items used a five-point Likert scale ranging from 1 'strongly disagree' to 5 'strongly agree'. Measurement items can be found in Table A1 in the appendix. Data were collected from visitors ECOS festivities and the Manchester Science Festival in Manchester, UK, over the festival period from summer to autumn in 2016. Participants tried a mobile based AR application at Manchester city center before completing a questionnaire. Data 
collection took place in front of Manchester's Central Library, one of main points of interests for tourists coming to the city and close to major tourist attractions. The AR application was designed as a science tour, and therefore, as part of this study, participants were asked to visit four sites close to the study site and enhanced through AR. A systematic random sampling was used, and 220 usable questionnaires were collected. According to Shenton (2004) random sampling as allows collecting representative samples because it includes findings from the general population. Every tenth visitor was approached, and researchers asked whether these visitors were tourists to ensure that only tourists participated in this study. Residents were excluded, and tourists overall had a favorable attitude toward participating. A confident interval approach was used to determine a sample size of 239 for $95 \%$ accuracy at the $95 \%$ confidence level (Burns and Bush, 1995). A total of 575 (575/0.4) tourists were approached to participate in the survey, assuming a response rate of $50 \%$ and an unusable rate of $10 \% ; 220$ usable surveys were collected after excluding any non-usable data. Participants were provided with a mobile phone and a map of the AR content to ensure that every visitor had the same experience. The AR content from four different sites was triggered by iBeacons once participants were close to the sites, which included statues, buildings, or monuments. The content included audio, videos, animations, or simply text information about the science heritage of Manchester. The AR experience lasted approximately 30 minutes, and afterwards participants were asked to fill in a questionnaire about their experience. All participants who participated in the AR experience completed the questionnaire at the end of the experiment. The sample included 124 (56.4\%) males and $96(43.6 \%)$ females. About 60\% (128) of the respondents were between 18 and 24 years old, $25 \%$ (54) were 25 to 34 years old, and the rest were older than 35 . In terms of education level, near half of the respondents (45.5\%) held an undergraduate degree, $27.7 \%$ had 
postgraduate degrees, and $16.4 \%$ had A-levels. More than half the respondents $(51.8 \%)$ earned less than $£ 20,000$ and were students. Detailed information on respondent profiles is provided in Table A2 in the appendix.

\section{Data analysis}

A set of preliminary tests evaluated the reliability and validity of measures. Several drawbacks/assumptions of SEM such as multicollinearity issue, data normality, and necessity of a large sample size are addressed by the asymmetrical approach (Olya and Altinay, 2016). We believe that asymmetrical comparison of SEM and symmetrical approaches by exploring causal recipes (not net effect of the factors) provides different insights on visitor engagement. Specifically, fsQCA enables us to calculate recipes for negation of the outcome (i.e., visitor engagement) that do not simply mirror opposite recipes for high engagement. In symmetrical analysis, models for low outcome are simply considered mirror opposites of models for high level of outcome, which is not realistic or pragmatic because both recipes are unique.

fsQCA requires three steps: calibration, generating truth table analysis, and counterfactual analysis. These steps were performed to explore causal recipes (i.e., complex combinations of predictors) on the model outcome. In the calibration step, crisp data, measured using a Likert scale, was transformed to fuzzy data. Then, truth tables, a list of all possible causal conditions leading to the outcome, were calculated based on the Boolean algebra function. In counterfactual analysis, sufficient and consistent causal recipes were extracted from the truth table using two probabilistic measures: coverage and consistency (Olya and Gaviliyan, 2017; Ragin, 2008). The recommended threshold for coverage is 0.2 ; for consistency, the threshold is 0.7. Coverage and consistency in asymmetric modelling are analogous to the coefficient of determination $\left(\mathrm{R}^{2}\right)$ and correlation coefficient (r) in symmetric analyses (Olya et al., 2019; Ragin 
2008; Wu et al., 2014). Analysis of necessary conditions identified the conditions necessary to achieve the given outcome (Dul, 2016; Olya and Akhshik, 2019). Managers can allocate their resources to manage conditions that meet necessary values. Consistency with higher value of 0.9 is the threshold for necessary conditions (Olya and Han, 2019). fsQCA and analysis of necessary conditions were conducted using fsQCA software.

\section{Results}

\section{Reliability and validity}

Table 1 shows that all factor loadings were significant at $\mathrm{p}<.001$ and well above 0.70 , which is the recommended threshold. Furthermore, composite reliability (CR), average variance extracted (AVE), and Cronbach's alpha ( $\alpha$ ), all exceeded their respective recommended thresholds of 0.7 , 0.5 , and 0.7 . Table 1 also reports the results of descriptive statistics including means, standard deviations, skewness, and kurtosis values for scale items. The results indicate that data were normally distributed because the values for skewness and kurtosis fall within the commonly accepted range of \pm 2 (Field, 2009; Gravetter and Wallnau, 2014).

\section{--- Insert Table 1 Here ---}

Finally, as shown in Table 2, discriminant validity was checked using the Fornell and Larcker (1981) procedure. Discriminant validity was ensured, with all AVE values above the squared construct correlations as suggested by Hair et al. (2006).

--- Insert Table 2 Here --- 


\section{fs $Q C A$ results}

This study extends previous research by tom Dieck et al. (2018), which examined only the relationships among visitor experience, memory, satisfaction, and engagement when AR was used as part of the science festival experience. To further extend the research and contribute to the pool of knowledge, we investigated the effects of visitor demographics on the level of satisfaction and memory as well as the effect on visitor engagement of prior AR experience.

Table 3 presents fsQCA results from demographic configurations in predicting memories (A), satisfaction (B), and engagement of visitors (C). Three models explain profiles of visitors with memorable experiences (Table 3, A: coverage: .512, consistency: .851). Model 1 shows that visitors who are male and educated with low income levels remember their visit as a memorable experience. Model 2 indicates that older females with low income levels have memorable experiences. According to Model 3, older males who are educated have memorable experiences as well. Two models describe profile of visitors who do not have memorable experiences (Table 3, A: coverage: .333, consistency: .719). Model 1 shows older visitors with low incomes, but educated, are less likely remember their visit as memorable. Model 2 indicates that older single males who are educated do not have memorable experiences.

Three models explain the profiles of satisfied visitors (Table 3. B: coverage: .936, consistency: .823). According to Model 1, satisfied visitors are young with low income levels. Model 2 shows that female visitors with low income levels have satisfactory experiences. Model 3 indicates that older males who are educated are most likely satisfied with their experiences. Two models describe conditions that cause dissatisfaction (Table 3. B: coverage: .304, consistency: .688). Model 1 shows that older females who are educated and have low incomes 
are most likely to be dissatisfied. Alternatively, older males with high income levels and high educational backgrounds are not satisfied with their experiences (Model 2).

Two models from demographics configuration describe conditions where visitors are engaged with the festival activities during their visit (Table 3. C: coverage: .369, consistency: .795). Model 1 shows younger males with low income levels who have prior experience with AR express high levels of engagement. According to Model 2, younger females with low incomes, educated but without prior experience with AR, become engaged with AR activity. Two models explain profiles of disengaged visitors (Table 3. C: coverage: .234, consistency: .794). According to Model 1, older visitors who are educated and have prior experience with AR but have low incomes are less likely to become engaged in the festival. Model 2 indicates that educated females with high incomes and without prior experience with AR might not engage with festival activities.

--- Insert Table 3 Here ---

Table 4 shows the results of configurational modelling for predicting high and low scores of memories and satisfaction via AR experience in the context of science festival. According to fsQCA results, three causal models describe conditions that lead to high memory scores (Table 4. D: coverage: .936, consistency: .806). Model 1 indicates that high education and low escapism is sufficient to achieve high memories. In other words, visitors with wonderful memories of the experience found AR was informative, involving less escapism. Alternatively, Model 2 suggests that high memory scores are achieved if visitors rated entertainment high and escapism low. That is, visitors did find escapism in the AR experience, but it was the entertainment aspect that made 
the experience memorable. According to Model 3, high aesthetics, education, and entertainment resulted in high memory scores, so a memorable AR experience was created by aesthetics, information, and entertainment in the AR program.

\section{--- Insert Table 4 Here ---}

The conditions for low memory scores are shown on right side of Table $4(\sim \mathrm{D})$. Three causal models show conditions where visitors did not find AR a memorable experience (coverage: .733, consistency: .733). Model 1 shows that low aesthetics and low escapism in an AR experience lead to low memory scores among visitors. This means that festivals without a sense of aesthetics and escapism are less likely to be memorable scientific events. Alternatively, high education and low entertainment and escapism describe a condition of low memory scores (Model 2). In other words, a group of visitors who rated a low level of memories believed that the festival was an educational, but neither entertaining nor escapist. In Model 3, high entertainment, low education, and escapism result in low memory scores. The group of visitors with low memories appreciated the entertaining aspect of the festival but believed it was neither educational nor escapist. Comparing the results of fsQCA for high and low memory scores revealed that causal models for high memory scores are not mirror opposites of causal models for low memory scores (Table 4).

The results of fsQCA offer three causal models for high levels of satisfaction (Table 4, E: coverage: .902, consistency: .945). The recipes for these three causal models are similar to models that lead to high memory scores (cf., D and E in Table 4). Model 1 showed that high education and low escapism satisfy visitors using AR. This means that although some visitors 
may not find the festival an escapist event, still its informative aspect satisfies them. Model 2 indicates that high entertainment and low escapism describe a condition where high satisfaction is achieved. This suggests that satisfied visitors find the festival as an entertaining event, but not an escapist one. Model 3 explains that high satisfaction is caused by high aesthetics, education, and entertainment. In other words, satisfied visitors enjoyed the aesthetics, education, and entertainment aspects of the festival. As Table 4 shows, two causal models describe conditions of low satisfaction. Specifically, AR with low levels of aesthetics, entertainment, and escapism leads to low visitor satisfaction (Table 4, E: Model 1), while in Model 2 low levels of aesthetics, education, and escapism result in low satisfaction.

The causal models for high and low engagement in a science festival obtained from evaluation of experience configuration are provided in Table 5. Two causal models explain conditions of high visitor engagement (coverage: .669, consistency: .772). According to fsQCA results, high visitor satisfaction results in high levels of engagement (Table 5, F: Model 1). That is, visitors who are satisfied are most likely to become engaged in the festival activity. Interestingly, visitors who experienced the AR application and had a low rate of memories are most likely engage in the science festival (Model 2). This means that visitors with low memories engaged in the science festival due to their past experiences with AR. These results highlight the importance of past experience with AR in visitor engagement in such events. According to fsQCA results for the low levels of engagement shown in Table $5(\sim \mathrm{F})$, low visitor engagement is caused by low memories and low satisfaction with the AR (Model 1- coverage: .523, consistency: .928). In other words, poor memories and low satisfaction results in low engagement. 
The fsQCA results from two configurations of 'experience economy' and 'evaluation of experience' are outlined in Table $6(\mathrm{G})$. Five causal models describe the complex conditions required to achieve high engagement (coverage: .856, consistency: .878). Model 1 indicates that high aesthetics, education, entertainment, escapism, memories, and satisfaction result in high engagement. According to Model 2, high aesthetics, education, entertainment, satisfaction, and past experience with AR lead to high engagement. Model 3 suggests that high engagement can be obtained if the AR has aesthetic appeal, entertainment, memorability, even if the AR has less escapism and visitors have no experience with AR. A high level of engagement among visitors without experience comes from high aesthetics, education, satisfaction, memories, and low escapism (Model 4, Table 6). Model 5 shows that high education, entertainment, memories, and satisfaction, even with low escapism, was more likely to lead to high engagement among visitors with past experience of AR.

--- Insert Table 6 Here ---

The fsQCA results for low engagement $(\sim \mathrm{G})$ show five causal recipes (coverage: .860, consistency: .766). Model 1 indicates that low aesthetics, education, entertainment, and escapism leads to low engagement of visitors with past experience of AR. Alternatively, Model 2 shows that low memories and high aesthetics, education, entertainment, and satisfaction leads to low engagement among visitors experienced in AR. According to Model 3, low education and escapism with high aesthetics, entertainment, memories, and satisfaction lead to low scores for 
engagement among visitors without past AR experience. Model 4 indicates that low engagement of visitors experienced with AR is caused by low entertainment and escapism and high aesthetics, education, memories, and satisfaction. Model 5 shows that low aesthetics and escapism and low education, entertainment, memories, and satisfaction cause low engagement among visitors with past experience with AR. The results showed that the causal models for high scores in the study outcomes are unique and not mirror opposites of low outcome scores.

\section{Analysis of necessary conditions}

The results of analyses of necessary condition are provided in Table 7. Necessary conditions are those factors that satisfied commonly accepted levels of consistency (consistency $>$.9) (Dul, 2016; Olya and Al-ansi, 2018). Aesthetics, education, and entertainment are three necessary conditions to achieve memorable AR experience among visitors to the science festival. Education and entertainment are two necessary conditions to satisfy visitors. For high engagement among visitors, aesthetics, education, entertainment, and satisfaction are necessary conditions (Table 7).

\section{--- Insert Table 7 Here ---}

\section{Discussion and conclusion}

This study contributes to the current knowledge of festival visitor behaviors using asymmetrical modelling of visitor responses to experience economy in situations where AR is part of their science festival experience. This study extended a recent study by tom Dieck et al. (2018) by moving beyond symmetrical thinking and applying fsQCA as a set-theory approach to explore the complex configuration of an experience economy along with past experience in predicting 
memories, satisfaction, and engagement of festival visitors who used AR. fsQCA is a powerful and pragmatic approach for creating knowledge by exploring combinations of factors that explain conditions leading to high and low scores of outcomes (Kan et al., 2016; Olya et al., 2019).

The results of fsQCA could inspire festival organizers to create an action plan that uses the four antecedents of the experience economy, leading to a higher level of visitor memories and satisfaction via AR and then actual engagement with the science festival. Managers must be vigilant for recipes for low memories, satisfaction, and engagement. Furthermore, necessary factors from the experience economy obtained from NCA are crucial conditions that must be satisfied during such events to make sure expected outcomes are achieved.

Testing the structural model of tom Dieck et al. (2018) showed that visitor engagement is significantly and positively influenced by memories and satisfaction, which are affected by education and entertainment. They also found that escapism is sufficient to predict memories but insufficient to increase satisfaction. Indeed, our study shows clearly that festival and tourism experiences are not static, and certain experience economy factors may or may not influence visitor engagement. Instead, complex interrelations among aesthetics, education, entertainment, and escapism experience through AR can influence visitor satisfaction and the creation of memorable experiences that lead to engagement with science experience. This means that prior experience is immensely important, one of the most important influences in determining which antecedent leads to visitor engagement.

While SEM offers insight into sufficient net effect and fsQCA into the complex configurations of the antecedents, analysis indicates that festival managers must stress necessary conditions to obtain the desired outcomes of memories, satisfaction, and visitor engagement (Dul, 
2016; Olya and Al-ansi, 2018). To the best of our knowledge, this research is among the first empirical studies that includes fsQCA and NCA to model memories, satisfaction, and engagement.

By applying a configurational model, this study revealed several causal recipes that describe sufficient complex conditions for these outcomes. In accordance with Olya and Akhshik (2019), a combination of antecedents (e.g., aesthetics and education) describe causal conditions leading to desired responses among festival visitors, and in line with Olya et al. (2018), it is rare that a single antecedent sufficiently describes a causal recipe of behavioral intention. A summary of fsQCA results with a different presentation is provided in Table A3 in the appendix. Our study found that, other than the causal model shown in Table A3. F: M1, all causal recipes comprise more than one antecedent. These results reveal that visitor engagement requires a complex interaction of the antecedents. For example, visitors who have past AR experience are more likely to become engaged when AR is aesthetic, informative, and entertaining, a recipe that satisfies these visitors (Table A3. G: M2).

This study provides new insights for the AR industry and academia by using a different analytical approach for solving complex interactions of the experience economy factors along with past experiences of visitors. This empirical study showed that causal recipes for achieving a high outcome level (e.g., high engagement) are not simply mirror opposites of the causal recipes for low level outcomes (e.g., low engagement) (Wu et al., 2014). For example, while high satisfaction is sufficient for high engagement (Table A3. F: M1), low satisfaction by itself does not lead to low engagement. In fact, a combination of low memory and satisfaction scores describes a condition of low engagement (Table A3. F: M1). 
In essence, our study shows how antecedents contribute to achieving high engagement and how their role varies based on the features of other antecedents in a causal recipe for engagement. For example, entertainment in causal models 1 and 4 affect engagement negatively, but entertainment contributes to predicting low engagement in models 2, 3, and 5 (see Table A3. $\sim$ G). Such results justify using heterogeneous antecedents to predict behavioral responses of visitors, confirming the findings of Olya and Gavilyan (2017) and Wu et al. (2014), who reported antecedents acting both positively and negatively, depending on the attributes of other antecedents, on behavioral outcomes. These results also show that visitor behavior is complex because several antecedents with heterogeneous roles must be combined to predict visitor engagement (Table A3). These results parallel the findings of Pappas (2017) and Olya and Akhshik (2019), who used configurational modelling to tackle the complexity of individual behaviors. Practitioners must see the complexity of the task of creating tourism and festival experiences; multiple factors contribute to creating memorable, satisfying, and ultimately engaging experiences.

Therefore, the findings from fsQCA showed that high levels of visitor engagement can be achieved through five causal recipes (Table A3). As Olya, Altinay, and De Vita (2018) noted, unlike symmetric approaches, fsQCA helps generate knowledge by exploring alternative models to predict a desired outcome. Our results do demonstrate the complexity of the human behavior, but they can also provide an action plan for festival organizers in managing conditions to help visitors improve memories, satisfaction, and engagement. For example, education and entertainment (Nicholson et al., 2001) are two features of AR that are necessary to satisfy and engage visitors who use technology for storytelling and better delivery of experience and 
consequently have good memories (Shin, 2018; tom Dieck et al., 2018; van Winkle et al., 2018) of their festival visit.

Apart from their theoretical contribution, such findings also provide implications for practitioners and decision makers. The results of this study indicate that festival managers and DMOs must know which factors are critical to visitor satisfaction and memorable experiences (Pan and Huan, 2013; Shin, 2018) via AR and then engage them with the festival. Furthermore, it is important for festival managers and managers of DMOs to follow sufficient recipes (i.e., combinations of factors) and satisfy necessary predictors of visitor memories and satisfaction using AR for visitor engagement with the festival (Robertson et al., 2015). In addition, aesthetics, education, and entertainment of the AR experience at science festivals appeared to encourage actual visitor engagement. Therefore, festival managers and AR application developers must work together to ensure that AR applications for science festivals have visually appealing and attractive (aesthetics) designs using high graphic or visual effects. In addition, they should provide relevant information for science education through the AR experience. Further, they must consider experience similar to gaming by using emojis or appealing objects to provide visitors an entertaining AR experience. Understanding the causal conditions required for high levels of visitor memories, satisfaction, and engagement means festival organizers can see what is unique and different about those conditions, particularly that they involve more than their mirror opposites in causal models of negation. Specifically, festival organizers must understand that low visitor memories and satisfaction lead to low engagement, but high visitor memories and satisfaction will not necessarily result in high engagement (Table A3). Managers can use Table A3 as a guideline to which combinations of factors are sufficient to predict high/low scores of memories, satisfaction, and engagement. 
To create memorable science festival experiences that engage visitors in the long term, public-private partnerships and collaborations, facilitated by DMOs, can be considered a key to providing a long lasting effect. Although AR can facilitate engagement, DMOs must ensure that public and private content is continuously created, maintained, and promoted by a wide audience within destinations to ensure future success. In particular, the involvement of small businesses can boost the impact on the local community and economy while providing an enhanced experience for visitors.

The results of this study took one step past the study by tom Dieck et al. (2018), which examined the relationship among visitor experience, memory, satisfaction, and visitor engagement. In this study, we investigated the influence of demographics on visitor satisfaction and memory as well as the effect of prior AR experience on visitor engagement. More specifically, a combination of demographic factors (age, gender, education, income, and marital status) affect the AR science festival experience. For instance, older females with low incomes (model 2) and older males who are educated (model 3) have more memorable experiences than other visitors. Furthermore, prior experience influences visitor engagement at science festivals. Prior experience depends on attributes of other predictors in the causal recipes. Specifically, prior experience has a positive effect on engaging young male visitors with low incomes. In contrast, no prior experience increase engagement of old female educated couples with low income level (c.f. Table 3. C).

In terms of education level and marital status, educated visitors are most likely to express the desired responses in terms of memories, satisfaction, and engagement. These results are different from Al-Ansi et al. (2019) who found heterogeneous role of marital status in increase of consumer's satisfaction and loyalty. In addition, this study found that people with low incomes 
were more satisfied with AR related science festival activities, possibly because of their general low exposure to this relatively new technology. This is in line with Olya et al. (2018) who found tourists with low income levels are more satisfied and loyal. Unlike Olya et al. (2019), this study revealed that scores of memory, satisfaction and engagement for coupled/married visitors are more than single visitors. One possible reason for this result is when visitors are with their partners, they might remember the science festival as a memorable event where they enjoyed their engagement and company. To have more satisfied visitor with engaging atmosphere, marketers need to target coupled/married visitors. Older people, for instance, had more memorable experiences when using AR. This is similar to Islam et al.'s (2018) findings that indicate old people get more engaged in tourism activities. Therefore, content design is particularly important to create memories and good experiences for the elder target market. Different from Gannon et al. (2019), this study found prior experience may play both positive and negative roles in predicting engagement of visitors in science festival. This is promising for organizer of science festival as prior experience is not a prerequisite for increasing engagement of visitors and less efforts are needed to ensure loyalty of visitors in this context. For DMOs and festival marketing organizations, this provides important contributions for target marketing. In fact, to design effective AR experiences, this study shows that memory, satisfaction, and engagement of visitors are affected by their demographics.

Our study does have some limitations. First, we conducted our study at one destination in a single application and therefore, the findings may not generalize to other science festivals. Second, our study explored the AR experience at science festivals based on the perspective of visitors, so future research should explore the differences between visitors and other stakeholders (e.g., residents and organizers) to more fully explicate differences in engagement behavior. 
Finally, our study used the experience economy as a theoretical foundation and thus may have neglected additional factors that influence memories, satisfaction, and engagement at science festivals. Therefore, we recommend studying context-specific AR engagement factors at science festivals. Finally, for strengthening the argument on the contribution that fsQCA can make to our understanding of factors motivating return visits to science festivals, future studies should consider incorporating the experiential-hedonic perspective overlying the experience economy paradigm to better explain the complexity of visitor experiences.

\section{Appendix}

--- Insert Table A1 Here ---

--- Insert Table A2 Here ---

--- Insert Table A3 Here ---

--- Insert Table A4 Here --- 


\section{References}

Al-Ansi, A., Olya, H. G., and Han, H. (2019). "Effect of general risk on trust, satisfaction, and recommendation intention for halal food", International Journal of Hospitality Management, Vol. 83, pp. 210-219.

Bronfenbrenner, U. (1994). "Ecological models of human development", Readings on the Development of Children, Vol. 2 No. 1, pp. 37-43.

Bultitude, K. (2014), "Science festivals: do they succeed in reaching beyond the already engaged?", Journal of Science Communication, Vol. 13 No. 4, pp. 1-3.

Burns, A. C. and Bush, R. F. (1995), Marketing research. Englewood Cliffs, NJ: Prentice Hall.

Chang, S. (2018a), "Experience economy in hospitality and tourism: Gain and loss values for service and experience", Tourism Management, Vol. 64, pp. 55-63.

Chang, S. (2018b). "Experience economy in the hospitality and tourism context", Tourism Management Perspectives, Vol. 27, pp. 83-90.

Chapman, S. (2017), "Historic cities to get $£ 1$ million augmented reality tourism boos", available at: https://www.prolificnorth.co.uk/digital/2017/10/historic-cities-get-\%C2\%A31-millionaugmented-reality-tourism-boost (accessed 26 June 2017)

Chung, N., Han, H. and Joun, Y. (2015). “Tourists' Intention to Visit a Destination: The Role of Augmented Reality (AR) Application for a Heritage Site", Computers in Human Behavior, Vol. 50, pp. 588-599.

Dul, J. (2016), "Identifying single necessary conditions with NCA and fsQCA", Journal of Business Research, Vol. 69 No. 4, pp. 1516-1523. 
Felsenstein, Daniel, and Aliza Fleischer. "Local festivals and tourism promotion: The role of public assistance and visitor expenditure." Journal of Travel Research, Vol. 41 No. 4, pp. 385-392.

Field, A. (2009), Discovering statistics using SPSS. London: SAGE.

Gannon, M., Taheri, B. and Olya, H. (2019), "Festival quality, self-connection, and bragging", Annals of Tourism Research, Vol. 76, pp. 239-252.

Georgiou, Y. and Kyza, E. A. (2017), "The development and validation of the ARI questionnaire: An instrument for measuring immersion in location-based augmented reality settings”, International Journal of Human-Computer Studies, Vol. 98, pp. 24-37.

Gim, G. C. and Ramayah, T. (2019), "Predicting turnover intention among auditors: Is WIPL a mediator?" The Service Industries Journal, pp. 1-27. DOI: $\underline{10.1080 / 02642069.2019 .1606214 .}$.

Gravetter, F. and Wallnau, L. (2014), Essentials of statistics for the behavioral sciences, 8th ed, Belmont, CA: Wadsworth.

Han, D. I. and Jung, T. (2018), “Identifying Tourist Requirements for Mobile AR Tourism Applications in Urban Heritage Tourism", In Jung, T. \& tom Dieck, M.C. (Eds.). Augmented Reality and Virtual Reality, Springer, Cham, pp. 3-20.

Han, D., Jung, T. and Gibson, A. (2014), "Dublin AR: Implementing Augmented Reality (AR) in Tourism," In Xiang, Z. and Tussyadiah, I., Information and Communication Technologies in Tourism. Springer, Heidelberg, pp. 511-523.

Haugstvedt, A. C. and Krogstie, J. (2012, November), "Mobile augmented reality for cultural heritage: A technology acceptance study", Paper presented at the IEEE International 
Symposium on Mixed and Augmented Reality 2012 Science and Technology Proceedings, Atlanta, USA.

Hosany, S. and Witham, M. (2009), 'Dimensions of cruisers' experiences, satisfaction, and intention to recommend", Journal of Travel Research, Vol. 49 No. 3, pp. 351-364.

Huang, S. and Hsu, C. H. (2009), "Effects of travel motivation, past experience, perceived constraint, and attitude on revisit intention", Journal of Travel Research, Vol. 48 No. 1, pp. $29-44$.

Islam, J. U., Rahman, Z. and Hollebeek, L. D. (2018), “Consumer engagement in online brand communities: a solicitation of congruity theory", Internet Research, Vol. 28 No. 1, pp. 2345.

Jung, T., tom Dieck, M. C., Lee, H. and Chung, N. (2016), "Effects of virtual reality and augmented reality on visitor experiences in museum", In Inversini, A. and Schegg, R. (Eds.), Information and Communication Technologies in Tourism 2016. Springer, Heidelberg, pp. 621-635.

Kahneman, D., and Thaler, R. (1991). "Economic analysis and the psychology of utility: Applications to compensation policy", The American Economic Review, Vol. 81 No. 2, pp. 341-346.

Kim, S., Ham, S., Moon, H., Chua, B. L., and Han, H. (2019). "Experience, brand prestige, perceived value (functional, hedonic, social, and financial), and loyalty among GROCERANT customers", International Journal of Hospitality Management, Vol. 77, pp. $169-177$.

Kouper, I. (2010), "Science blogs and public engagement with science: Practices, challenges, and opportunities", Journal of Science Communication, Vol. 9 No. 1, pp. 1-10. 
Leshner, A.I. (2003), "Public engagement with science”, Science, Vol. 299 No. 5609, pp. 977 977.

Loureiro, S. M. C. (2014), "The role of the rural tourism experience economy in place attachment and behavioral intentions", International Journal of Hospitality Management, Vol. 40, pp. 1-9.

Mazursky, D. (1989). "Past experience and future tourism decisions", Annals of Tourism Research, Vol. 16 No. 3, 333-344.

Manthiou, A., Lee, S., Tang, L. and Chiang, L. (2014), “The experience economy approach to festival marketing: Vivid memory and attendee loyalty", Journal of Services Marketing, Vol. 28 No. 1, pp. 22-35.

Mehmetoglu, M. and Engen, M. (2011), "Pine and Gilmore's concept of experience economy and its dimensions: An empirical examination in tourism", Journal of Quality Assurance in Hospitality \& Tourism, Vol. 12 No. 4, pp. 237-255.

Moorhouse, N., tom Dieck, M. C. and Jung, T. (2017), “Augmented Reality to enhance the Learning Experience in Cultural Heritage Tourism: An Experiential Learning Cycle Perspective", eReview of Tourism Research, Vol. 8, pp. 1-5.

Nicholson, R. E. and Pearce, D. G. (2001), "Why do people attend events: A comparative analysis of visitor motivations at four South Island events", Journal of Travel Research, Vol. 39 No. 4, pp. 449-460.

Neuburger, L. and Egger, R. (2018), “Augmented reality: Providing a different dimension for museum visitors", In Jung, T. \& tom Dieck, M.C. (Eds.), Augmented reality and virtual reality, Springer, Cham, pp. 65-77. 
Oh, H., Fiore, A. M. and Jeoung, M. (2007), "Measuring experience economy concepts: Tourism applications", Journal of Travel Research, Vol. 46 No. 2, pp. 119-132.

Olya, H. and Akhshik, A. (2019), "Tackling the complexity of the pro-environmental behaviors of visitors to marine turtle sites", Journal of Travel Research, Vol. 58 No. 2, pp. 313-332.

Olya, H., Altinay, G. Z., Altinay, A. F. and Altinay, M. (2018), "Behavioral intentions of disabled tourists for the use of peer-to-peer accommodations: An application of fsQCA", International Journal of Contemporary Hospitality Management, Vol. 30 No. 1, pp. 436-454.

Olya, H. G. and Altinay, L. (2016), “Asymmetric modeling of intention to purchase tourism weather insurance and loyalty”, Journal of Business Research, Vol. 69 No. 8, pp. 27912800.

Olya, H., Altinay, L. and De Vita, G. (2018), “An exploratory study of value added Services", Journal of Service Marketing, Vol. 32 No. 3, pp. 334-345.

Olya, H. G., and Gavilyan, Y. (2017). “Configurational models to predict residents' support for tourism development”, Journal of Travel Research, Vol. 56 No. 7, pp. 893-912.

Olya, H. G., and Han, H. (2019). “Antecedents of Space Traveler Behavioral Intention”, Journal of Travel Research, Doi: 0047287519841714.

Olya, H. and Mehran, J. (2017), "Modelling tourism expenditure using complexity theory", Journal of Business Research, Vol. 75, pp. 147-158.

Olya, H. G., Lee, C. K., Lee, Y. K. and Reisinger, Y. (2019), "What are the triggers of Asian visitor satisfaction and loyalty in the Korean heritage site?", Journal of Retailing and Consumer Services, Vol. 75 No. 47, pp. 195-205. 
Olya, H., Shahmirzdi, E. and Alipour, H. (2019), "Pro-tourism and anti-tourism community groups at a world heritage site in Turkey", Current Issues in Tourism, Vol. 22 No. 7, pp. $763-785$.

Ostrovskiy, A., Garkavenko, V. and Rybina, L. (2019), “Influence of socio-psychological factors on consumers purchasing behavior in Kazakhstan”, The Service Industries Journal, pp. 126. $\underline{10.1080 / 02642069.2019 .1601707}$.

Pan, B. and Huan, T. C. (2013), "New perspectives on festival and events research", International Journal of Culture, Tourism and Hospitality Research, Vol. 7 No. 2, pp. 115117.

Pappas, N. (2017), "The complexity of purchasing intentions in peer-to-peer accommodation", International Journal of Contemporary Hospitality Management, Vol. 29 No. 9, pp. 2302-2321.

Park, M., Oh, H. and Park, J. (2010), "Measuring the experience economy of film festival participants", International Journal of Tourism Sciences, Vol. 10 No. 2, pp. 35-54.

Pine, B. J. and Gilmore, J. H. (1998), “The experience economy”, Harvard Business Review, Vol. 76 No. 6, pp. 97-105.

Quadri-Felitti, D. and Fiore, A. M. (2013), "Destination loyalty: Effects of wine tourists' experiences, memories, and satisfaction on intentions", Tourism and Hospitality Research, Vol. 13 No. 1, pp. 47-62.

Ragin, C. C. (2008). Redesigning social inquiry: Fuzzy sets and beyond. Chicago and London: University of Chicago Press.

Rather, R. A., Hollebeek, L. D. and Islam, J. U. (2019), “Tourism-based customer engagement: 
the construct, antecedents, and consequences", The Service Industries Journal, pp. 1-22. Doi: $\underline{10.1080 / 02642069.2019 .1570154 .}$

Rauschnabel, P. A., Rossmann, A. and tom Dieck, M. C. (2017), “An adoption framework for mobile augmented reality games: The case of Pokémon Go", Computers in Human Behavior, Vol. 76, pp. 276-286.

Rivera, M., Semrad, K. and Croes, R. (2015), “The five E's in festival experience in the context of Gen Y: Evidence from a small island destination”, Revista Española de Investigación de Marketing ESIC, Vol. 19 No. 2, pp. 95-106.

Robertson, M., Yeoman, I., Smith, K. A. and McMahon-Beattie, U. (2015). "Technology, society, and visioning the future of music festivals", Event Management, Vol. 19 No. 4, pp. $567-587$.

Schreyer, R., Lime, D. W. and Williams, D. R. (1984). "Characterizing the influence of past experience on recreation behaviour", Journal of Leisure Research, Vol. 16 No. 1, pp. 3450.

Schugurensky, D. (2000). The forms of informal learning: Towards a conceptualization of the field. https://tspace.library.utoronto.ca/bitstream/1807/2733/2/19formsofinformal.pdf pp. $\underline{1-8}$.

Semrad, K. J. and Rivera, M. (2018), “Advancing the 5E's in festival experience for the Gen Y framework in the context of eWOM", Journal of Destination Marketing \& Management, Vol 7, pp. 58-67.

Shenton, A. K. (2004), "Strategies for ensuring trustworthiness in qualitative research projects", Education for Information, Vol. 22 No. 2, pp. 63-75. 
Shin, D. (2018), "Empathy and embodied experience in virtual environment: To what extent can virtual reality stimulate empathy and embodied experience?", Computers in Human Behavior, Vol. 78, pp. 64-73.

Song, H.J., Lee, C.K., Park, J.A., Hwang, Y.H., and Reisinger, Y. (2015). "The influence of tourist experience on perceived value and satisfaction with temple stays: The experience economy theory," Journal of Travel \& Tourism Marketing, Vol. 32 No. 4, pp. 401-415.

Stankov, U., Pavluković, V., Alcántara-Pilar, J. M., Cimbaljević, M., and Armenski, T. (2018), Should Festival Be Smarter?: ICT on Mass Events-The Case of the Exit Festival (Novi Sad, Serbia). In Handbook of Research on Technological Developments for Cultural Heritage and eTourism Applications (pp. 245-263). IGI Global.

Stilgoe, J., Lock, S. J. and Wilsdon, J. (2014), "Why should we promote public engagement with science?", Public Understanding of Science, Vol. 23 No. 1, pp. 4-15.

Thompson, N. (2016), "How technology is giving more life to festivals", Tech City News, Vol. 1, pp.1-1.

tom Dieck, M. C., Jung, T. H. and Rauschnabel, P. A. (2018), "Determining visitor engagement through augmented reality at science festivals: An experience economy perspective", Computers in Human Behavior, Vol. 82, pp. 44-53.

Tussyadiah, I., Jung, T. and tom Dieck, M. C. (2017), “Embodiment of Wearable Augmented Reality Technology in Tourism Experiences", Journal of Travel Research, Vol. 57 No. 5, pp. 597-611.

Van Winkle, C. M., MacKay, K. J. and Halpenny, E. (2018), Information and communication technology and the festival experience. In The Routledge Handbook of Festivals (pp. 254262). NY: Routledge. 
Wikström, S. R. (2008), “A consumer perspective on experience creation”, Journal of Customer Behaviour, Vol. 7 No. 1, pp. 31-50.

Woodside, A. G. (2014), “Embrace• perform• model: Complexity theory, contrarian case analysis, and multiple realities", Journal of Business Research, Vol. 67 No. 12, pp. 24952503.

Wu, P. L., Yeh, S. S., Huan, T. C. and Woodside, A. G. (2014), “Applying complexity theory to deepen service dominant logic: Configural analysis of customer experience-and-outcome assessments of professional services for personal transformations", Journal of Business Research, Vol. 67 No. 8, pp. 1647-1670.

Zach, F. J. and Tussyadiah, I. P. (2017), "To catch them all-the (un) intended consequences of Pokémon GO on mobility, consumption, and wellbeing", In Scheg, R. and Stangl, B. (Eds.), Information and Communication Technologies in Tourism 2017, Springer, Cham, pp. 217-227. 